\title{
Self-Generated or Cue-Induced-Different Kinds of Expectations to Be Considered
}

\author{
Maike Kemper $^{1 *}$ and Robert Gaschler ${ }^{2}$ \\ ${ }^{1}$ Interdisciplinary Research Cluster on Image, Knowledge, Gestaltung, Department of Psychology, Humboldt-Universität zu \\ Berlin, Berlin, Germany, ${ }^{2}$ Interdisciplinary Research Cluster on Image, Knowledge, Gestaltung, Department of Psychology, \\ FernUniversität in Hagen, Hagen, Germany
}

Keywords: stimulus expectation, self-generated expectations, predictions, cue-induced expectations, violation of expectation

\section{DIFFERENCES BETWEEN SELF-GENERATED AND CUE-INDUCED EXPECTATIONS}

Expectations can help humans to adequately prepare for action. Cognitive psychology has inspired studies on the influence of expectations on the course of scientific discovery (Klein and Roodman, 2005; Rzhetsky et al., 2006; Brewer, 2012). Violations of expectations in research often fail to provoke changes in theorizing and research practices. While expectations have been dissociated from other processes such as automatic response activation (Perruchet et al., 2006), relatively little attention has been devoted to reflecting on the different forms of expectation or different

OPEN ACCESS

Edited by:

Anna Thorwart,

University of Marburg, Germany

Reviewed by:

Mike Le Pelley,

University of New South Wales,

Australia

James R. Schmidt,

Ghent University, Belgium

*Correspondence:

Maike Kemper

maike.kemper@

psychologie.hu-berlin.de

Specialty section:

This article was submitted to

Cognition,

a section of the journal

Frontiers in Psychology

Received: 30 September 2016 Accepted: 10 January 2017

Published: 24 January 2017

Citation:

Kemper M and Gaschler R (2017)

Self-Generated or

Cue-Induced-Different Kinds of

Expectations to Be Considered.

Front. Psychol. 8:53.

doi: 10.3389/fpsyg.2017.00053 methods used to study expectations (and their violations). In this opinion paper, we highlight some early work (Acosta, 1982) and later contributions that have the potential to violate researchers' expectations on what seems the most suitable methodology for operationalizing expectations in the cognitive psychology lab.

In behavioral research, expectations are most often operationalized by assessing performance differences between trials in which expectations are met and trials in which expectations are violated. Neurophysiological data can assess dynamics before stimulus onset (e.g., Mattler et al., 2006; Kemper et al., 2012), and the mismatch effect shows that response times are faster and error rates lower for expected events (compared to when an expectation is violated). This can be demonstrated for expectations about stimuli (Posner and Snyder, 1975; Mattler, 2004), as well as to-be-performed tasks in task switching studies (Rogers and Monsell, 1995; Meiran, 1996). Furthermore, expectations can modulate the impact of cognitive conflicts (Duthoo et al., 2013, for a study on expectations in the Stroop task). The Gratton effect is a change in the strength of a conflict effect depending on the amount of cognitive conflict in previous trials. It has been described as an expectation effect (Gratton et al., 1992; see also Botvinick et al., 1999; Braver, 2012; but see e.g., Mayr et al., 2003; Schmidt and Weissman, 2016, for alternative interpretations).

Many studies use cues to induce stimulus expectations (Posner and Snyder, 1975; Shulman et al., 1999; Mattler, 2004; Oswal et al., 2007) and task expectations (Rogers and Monsell, 1995; Meiran, 1996). Other methods of inducing expectations include presentation of subliminal stimuli (Kunde, 2004) or irrelevant flankers (Nattkemper et al., 2010; Ziessler and Nattkemper, 2011). At first sight inducing expectations seems to offer a greater degree of experimental control compared to allowing participants to form their own expectations. By inducing expectations, experimenters can determine in advance how often which cue is used and how often the upcoming event violates vs. matches the expectation that the cue should induce. However, studies of stimulus expectations show stronger behavioral (Acosta, 1982) as well as EEG effects (Kemper et al., 2012) for selfgenerated compared to cue-induced expectations. This suggests that self-generated expectations might nonetheless be preferable, as they induce larger, and therefore more easily detectable, effects.

In a self-generated expectation condition, participants are prompted to verbalize their expectation (e.g., "shape?"). They verbalize which of the stimuli from the set (e.g., "circle") they 
are expecting to appear in the current trial. In a cuing variant, the participants are shown a picture of a circle or the word "circle" (cf. Kemper et al., 2012) and verbalize it. Next, the stimulus is shown and the response is collected. One early example hinting at a qualitative difference between self-generated vs. cue-induced expectations was reported by Acosta (1982). For mismatches, larger stimulus set sizes led to longer response times, for selfgenerated and cue-induced expectations alike, whereas for match trials, set size effects differed between cue-induced and selfgenerated expectations. Reaction times for stimuli that matched the cue were longer if more stimuli were used. For self-generated expectations, set size had only a minor influence. Presumably, the expected stimulus was strongly activated regardless of whether there were many or few alternative stimuli. In addition, Acosta (1982) reported evidence that violations of self-generated expectations have a stable effect when prolonging the interval between generation of the expectation and stimulus presentation whereas cue-induced expectations diminish relatively quickly for prolonged intervals. Stronger effects of violations of selfgenerated compared to cue-induced expectations have not only been obtained for expectations of stimuli. They were also found when expectations concerned a more abstract level of task processing, such as the conflict level of the upcoming trial (e.g., expecting a congruent vs. an incongruent Stroop trial; Kemper et al., 2016). Specifically, expecting the repetition of a congruent trial led to faster processing, while expecting conflict did not enhance performance (e.g., Duthoo et al., 2013). A modulation was found for self-generated expectations only.

Stronger effects of self-generated compared to cue-induced expectations can be attributed to (a) differences in strength and (b) likelihood of engagement. While there is evidence that cues can be ignored (especially in case of low validity; cf. Alpay et al., 2009), even chance-level validity leads to strong effects of selfgenerated expectations (e.g., Acosta, 1982; Kemper et al., 2012, 2016; Gaschler et al., 2014). This suggests that self-generated expectations cannot be ignored (see Schwager et al., 2016, for a current test of boundary conditions), whereas participants presumably fail to attend to or use cues of low validity in many of the trials. Based on this, and on the lack of a set size effect reported by Acosta (1982), Gaschler et al. (2014) suggested that the object of expectation becomes represented in the focus of attention in working memory (cf. Oberauer et al., 2013) in the case of self-generated expectations (but only occasionally so in the case of cues). This representation is accessible for verbal report, which implies that verbalizations are a rather direct measure of self-generated expectations. The stimulus representation that is activated more strongly than the others (if only by a small margin) can be selected for report.

More specifically, there is evidence for the assumption that this privileged form of representation is a by-product of selfassessing what one is currently expecting. Strong RT benefits for the stimulus that one says one is not expecting (Hacker and Hinrichs, 1979) or is expecting second most (Hacker and Hinrichs, 1974) suggest that the focus of attention in working memory is filled with the object one considers when self-assessing what one is currently expecting. Thus, researchers should take into account that self-generated verbalized expectations might not only serve as a measure of expectation, but also as a means of boosting expectation effects. Based on the evidence gathered so far, it is difficult to determine whether a stronger effect is in general desirable to increase the internal validity of the experiment or whether this comes at the cost of results that are only representative for the specific situation in which participants are required to form and verbalize an expectation. Studies that directly compare self-generated expectations when participants are either triggered to form them or can form them spontaneously have so far not been conducted. They might become possible using neurophysiological multivariate pattern recognition to trace expectations (cf. Cichy et al., 2014).

\section{RESTRICTED INFLUENCE OF EXPECTATION VIOLATIONS ON SELF-GENERATED EXPECTATIONS}

Self-generated expectations allow experimenters to track how violations of expectations influence the formation of future expectations. For example, expectations about the conflict level of an upcoming trial are highly dependent on the conflict level of the previous run of trials. For instance, participants expect a repetition of a conflict trial after one single conflict trial. However, the more conflict trials that have occurred in a row, the stronger participants show a gambler's fallacy and expect a congruent trial next (Jiménez and Méndez, 2013, 2014; Kemper et al., 2016). It is possible that violations of expectations operate like a conflict cue for processing in the upcoming trial. Exploring this possibility might help to further understand the differences between cue-induced and self-generated expectations.

In addition to effects of violation of expectation on future expectations that depend on the last (few) trial(s), stimulus probability influences the overall percentage in which participants predict each stimulus (e.g., Kemper et al., 2012). The phenomenon of probability matching (e.g., Umbach et al., 2012) suggests that self-generated expectations are not strategically chosen to optimize performance. For instance, if Stimulus A is $70 \%$ likely and Stimulus B is only $30 \%$ likely, probability matching means that participants will anticipate Stimulus A on $70 \%$ of the trials, and anticipate Stimulus B on $30 \%$ of the trials, even though to optimize performance (by optimizing the number of trials in which expectation and stimulus match) the best solution is to anticipate Stimulus A on $100 \%$ of the trials. In principle, participants could exclusively verbalize that they are expecting the frequent stimulus. This would maximize the number of match trials and should improve performance. Such strategic effects would undermine the credibility of verbalizations as a valid measure of expectations. However, participants match their expectations to the probabilities of stimuli instead of minimizing expectation violations (e.g., Kemper et al., 2012; Umbach et al., 2012). Expectations seem to be influenced by and to reflect stimulus frequencies. Future research should explore whether this influence is in part the result of (other) strategic effects. For example, participants might aim to match verbalization frequencies to stimulus frequencies in an attempt to obtain match trials even for the infrequent stimuli. In addition, 
probability matching can be an effect of the search for patterns (Gaissmaier and Schooler, 2008).

So far, the evidence for strategic effects is limited. The mismatch effect is stable with practice and of similar strength for frequent and infrequent stimuli, even though violations of expectations are much more likely for infrequent than for frequent stimuli (e.g., Umbach et al., 2012). Frequent violation of an expectation does not influence how strongly that expectation is relied upon in future trials. However, validity might have a different effect on cue induced than on selfgenerated expectations. Cues show larger mismatch effects when they are relatively valid (i.e., when the expectation is violated less often) and mismatch effects become very small for cues with low validity (e.g., Vossel et al., 2006).

\section{CONCLUSIONS FOR RESEARCH ON (THE VIOLATION OF) EXPECTATIONS}

Self-generated expectations show stronger effects than cueinduced expectations in a number of experimental setups, and measure expectations more effectively relative to cues. People still rely on self-generated expectations even if they are violated

\section{REFERENCES}

Acosta, E. (1982). Subjective and objective determinants of expectancy: similarities and differences. Am. J. Psychol. 95, 139-160. doi: 10.2307/1422664

Alpay, G., Goerke, M., and Stürmer, B. (2009). Precueing imminent conflict does not override sequence-dependent interference adaptation. Psychol. Res. 73, 803-816. doi: 10.1007/s00426-008-0196-9

Botvinick, M., Nystrom, L. E., Fissell, K., Carter, C. S., and Cohen, J. D. (1999). Conflict monitoring versus selection-for-action in anterior cingulate cortex. Nature 402, 179-181. doi: 10.1038/46035

Braver, T. S. (2012). The variable nature of cognitive control: a dual mechanisms framework. Trends Cogn. Sci. (Regul. Ed). 16, 106-113. doi: 10.1016/j.tics.2011. 12.010

Brewer, F. W. (2012). "The theory ladenness of the mental processes used in the scientific enterprise," in Psychology of Science: Implicit and Explicit Processes, eds R. W. Proctor and J. E. Capaldi (New York, NY: Oxford University Press), 289-334. doi: 10.1093/acprof:oso/9780199753628. 003.0013

Cichy, R. M., Pantazis, D., and Oliva, A. (2014). Resolving human object recognition in space and time. Nat. Neurosci. 17, 455-462. doi: 10.1038/nn.3635

Duthoo, W., Wühr, P., and Notebaert, W. (2013). The hot-hand fallacy in cognitive control: repetition expectancy modulates the congruency sequence effect. Psychon. Bull. Rev. 20, 798-805. doi: 10.3758/s13423-0130390-7

Gaissmaier, W., and Schooler, L. J. (2008). The smart potential behind probability matching. Cognition 109, 416-422. doi: 10.1016/j.cognition.2008.09.007

Gaschler, R., Schwager, S., Umbach, V. J., Frensch, P. A., and Schubert, T. (2014). Expectation mismatch: differences between self-generated and cue-induced expectations. Neurosci. Biobehav. Rev. 46, 139-157. doi: 10.1016/j.neubiorev. 2014.06.009

Gratton, G., Coles, M. G., and Donchin, E. (1992). Optimizing the use of information: strategic control of activation of responses. J. Exp. Psychol. Gen. 121:480. doi: 10.1037/0096-3445.121.4.480

Hacker, M. J., and Hinrichs, J. V. (1974). Multiple predictions in choice reaction time: a serial memory scanning interpretation. J. Exp. Psychol. 103, 999-1005. doi: $10.1037 /$ h0037396

Hacker, M. J., and Hinrichs, J. V. (1979). Verbal predictions of unexpected stimuli and choice reaction time. Mem. Cogn. 7, 505-510. doi: 10.3758/BF03198267 often (e.g., are of low validity in a long experiment). We suggest that researchers should take into account that the choice between self-generated and cue-induced expectations entails a tradeoff between the strength of the expectation effect and the degree of experimental control over expectations in individual trials. In addition, since internally-generated expectations may differ qualitatively from those induced by cues, it cannot be taken for granted that results obtained with one method can be generalized to situations involving the other.

\section{AUTHOR CONTRIBUTIONS}

MK and RG have written this article together. They have both contributed substantial, direct and intellectual contribution to the work, and approved it for publication.

\section{FUNDING}

This work was supported by the Interdisciplinary Research Cluster Image, Knowledge, Gestaltung (EXC1027/1), at Humboldt-Universität zu Berlin, Berlin.
Jiménez, L., and Méndez, A. (2013). It is not what you expect: dissociating conflict adaptation from expectancies in a Stroop task. J. Exp. Psychol. Hum. Percept. Perform. 39:271. doi: 10.1037/a0027734

Jiménez, L., and Méndez, A. (2014). Even with time, conflict adaptation is not made of expectancies. Front. Psychol. 5:1042. doi: 10.3389/fpsyg.2014.01042

Kemper, M., Gaschler, R., Schwager, S., and Schubert, T. (2016). The benefit of expecting no conflict-stronger influence of self-generated than cue-induced conflict expectations on Stroop performance. Acta Psychol. (Amst.). 163, 135-141. doi: 10.1016/j.actpsy.2015.11.008

Kemper, M., Umbach, V. J., Schwager, S., Gaschler, R., Frensch, P. A., and Stürmer, B. (2012). What I say is what I get: stronger effects of self-generated vs. cue-induced expectations in event-related potentials. Front. Psychol. 3:562. doi: 10.3389/fpsyg.2012.00562

Klein, J. R., and Roodman, A. (2005). Blind analysis in nuclear and particle physics. Annu. Rev. Nucl. Particle Sci. 55, 141-163. doi: 10.1146/annurev. nucl.55.090704.151521

Kunde, W. (2004). Response priming by supraliminal and subliminal action effects. Psychol. Res. 68, 91-96. doi: 10.1007/s00426-003-0147-4

Mattler, U. (2004). Combined expectancy effects are modulated by the relation between expectancy cues. Q. J. Exp. Psychol. A 57, 193-221. doi: 10.1080/0272 4980343000161

Mattler, U., van der Lugt, A., and Münte, T. F. (2006). Combined expectancies: electrophysiological evidence for adjusted expectancy effects. BMC Neurosci. 7:37. doi: 10.1186/1471-2202-7-37

Mayr, U., Awh, E., and Laurey, P. (2003). Conflict adaptation effects in the absence of executive control. Nat. Neurosci. 6, 450-452. doi: 10.1038/nn1051

Meiran, N. (1996). Reconfiguration of processing mode prior to task performance. J. Exp. Psychol. Learn. Mem. Cogn. 22:1423. doi: 10.1037/0278-7393.22.6.1423

Nattkemper, D., Ziessler, M., and Frensch, P. A. (2010). Binding in voluntary action control. Neurosci. Biobehav. Rev. 34, 1092-1101. doi: 10.1016/j.neubiorev.2009.12.013

Oberauer, K., Souza, A. S., Druey, M. D., and Gade, M. (2013). Analogous mechanisms of selection and updating in declarative and procedural working memory: experiments and a computational model. Cogn. Psychol. 66, 157-211. doi: 10.1016/j.cogpsych.2012.11.001

Oswal, A., Ogden, M., and Carpenter, R. H. (2007). The time course of stimulus expectation in a saccadic decision task. J. Neurophysiol. 97, 2722-2730. doi: 10.1152/jn.01238.2006 
Perruchet, P., Cleeremans, A., and Destrebecqz, A. (2006). Dissociating the effects of automatic activation and explicit expectancy on reaction times in a simple associative learning task. J. Exp. Psychol. Learn. Mem. Cogn. 32:955. doi: 10.1037/0278-7393.32.5.955

Posner, M. I., and Snyder, C. R. R. (1975). "Facilitation and inhibition in the processing of signals," in Attention and Performance V, ed P. M. A. Rabbit (London: Academic Press), 669-682.

Rogers, R. D., and Monsell, S. (1995). Costs of a predictible switch between simple cognitive tasks. J. Exp. Psychol. Gen. 124:207. doi: 10.1037/0096-3445.124.2.207

Rzhetsky, A., Iossifov, I., Loh, J. M., and White, K. P. (2006). Microparadigms: chains of collective reasoning in publications about molecular interactions. Proc. Natl. Acad. Sci. U.S.A. 103, 4940-4945. doi: 10.1073/pnas.0600591103

Schmidt, J. R., and Weissman, D. H. (2016). Congruency sequence effects and previous response times: conflict adaptation or temporal learning? Psychol. Res. 80, 590-607. doi: 10.1007/s00426-015-0681-x

Schwager, S., Gaschler, R., Rünger, D., and Frensch, P. A. (2016). Tied to expectations: predicting features speeds processing even under adverse circumstances. Mem. Cogn. doi: 10.3758/s13421-016-0683-y. [Epub ahead of print].

Shulman, G. L., Ollinger, J. M., Akbudak, E., Conturo, T. E., Snyder, A. Z., Petersen, S. E., et al. (1999). Areas involved in encoding and applying directional expectations to moving objects. J. Neurosci. 19, 9480-9496.
Umbach, V. J., Schwager, S., Frensch, P. A., and Gaschler, R. (2012) Does explicit expectation really affect preparation? Front. Psychol. 3:378. doi: 10.3389/fpsyg.2012.00378

Vossel, S., Thiel, C. M., and Fink, G. R. (2006). Cue validity modulates the neural correlates of covert endogenous orienting of attention in parietal and frontal cortex. Neuroimage 32, 1257-1264. doi: 10.1016/j.neuroimage.2006. 05.019

Ziessler, M., and Nattkemper, D. (2011). The temporal dynamics of effect anticipation incourse of action planning. Q. J. Exp. Psychol. 64, 1305-1326. doi: $10.1080 / 17470218.2011 .553067$

Conflict of Interest Statement: The authors declare that the research was conducted in the absence of any commercial or financial relationships that could be construed as a potential conflict of interest.

Copyright (c) 2017 Kemper and Gaschler. This is an open-access article distributed under the terms of the Creative Commons Attribution License (CC BY). The use, distribution or reproduction in other forums is permitted, provided the original author(s) or licensor are credited and that the original publication in this journal is cited, in accordance with accepted academic practice. No use, distribution or reproduction is permitted which does not comply with these terms. 